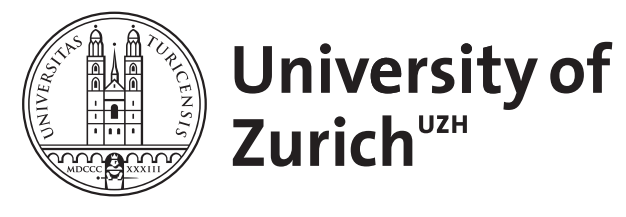

\title{
Risk-sorting and preference for team piece rates
}

\author{
Bäker, Agnes ; Mertins, Vanessa
}

\begin{abstract}
Incentive schemes not only influence the effort provision of workers, but might also induce sorting. As drivers of self-selection, the literature mainly focuses on measures of productivity; however, other variables, such as preferences, beliefs and personality, also play a role. With this paper, we contribute to the literature on drivers of self-selection by analyzing the role of perceived wage risks as potential influences on the sorting decision. To this end, we study a sorting decision between two variable compensation systems, where both options carry wage risks. Specifically, we look at sorting between individual piece rates and team piece rates. Using experimental data, we find evidence for both risk diversification considerations and free-riding concerns (i.e., risk of teaming-up with low-productive teammates) as drivers of self-selection. However, our data does not support the concern of our experimental subjects that others actually reduce their effort when working under team compensation, as compared to individual-based compensation.
\end{abstract}

DOI: https://doi.org/10.1016/j.joep.2012.10.010

Posted at the Zurich Open Repository and Archive, University of Zurich

ZORA URL: https://doi.org/10.5167/uzh-173464

Journal Article

Accepted Version

Originally published at:

Bäker, Agnes; Mertins, Vanessa (2013). Risk-sorting and preference for team piece rates. Journal of Economic Psychology, 34(February):285-300.

DOI: https://doi.org/10.1016/j.joep.2012.10.010 


\title{
Risk-sorting and preference for team piece rates
}

\author{
Agnes Bäker ${ }^{\mathrm{a}}$, Vanessa Mertins ${ }^{\mathrm{b}}$
}

Incentive schemes not only influence the effort provision of workers, but might also induce sorting. As drivers of self-selection, the literature mainly focuses on measures of productivity; however, other variables, such as preferences, beliefs and personality, also play a role. With this paper, we contribute to the literature on drivers of self-selection by analyzing the role of perceived wage risks as potential influences on the sorting decision. To this end, we study a sorting decision between two variable compensation systems, where both options carry wage risks. Specifically, we look at sorting between individual piece rates and team piece rates. Using experimental data, we find evidence for both risk diversification considerations and free-riding concerns (i.e., risk of teaming-up with lowproductive teammates) as drivers of self-selection. However, our data does not support the concern of our experimental subjects that others actually reduce their effort when working under team compensation, as compared to individual-based compensation.

\footnotetext{
a Department of Human Resource Management \& Organization, Eberhard Karls Universität Tübingen, 72074 Tübingen, Germany

bI nstitute for Labour Law and Industrial Relations in the European Community IAAEG), University of Trier, 54286 Trier, Germany
} 
A central finding in the organizational economics literature is that different incentive contracts can cause output differences not only with the incentive effects but also with the sorting effects (e.g., Curme \& Stefanec, 2007; Eriksson \& Villeval, 2008; Lazear, 2000). Productivity, however, is not the only driver of self-selection: individuals' preferences, beliefs, and personality dimensions influence sorting decisions, too. The sorting literature mostly focuses on the choice between fixed and variable payment schemes. In these decision situations, theoretical predictions and empirical findings rarely differ. For instance, riskaverse workers are more likely to self-select into fixed rather than variable payment schemes (Dohmen \& Falk, 2011). Given that fixed payment schemes carry no wage risk but variable payment systems do, this finding is not surprising. The situation is fundamentally different if we analyze sorting within two variable payment schemes because both carry wage risks. Here, the sorting behavior of rational agents should depend on their expectations of the agents' own and others' performance, making predicting outcomes much more difficult. This paper focuses on self-selection within variable payment schemes and analyzes the role of risks in sorting.

We analyze sorting between incentive systems where payment is based on individual output (here individual piece rates) or team output (here team piece rates). These schemes mainly differ regarding (1) whether payoffs depend on one's own performance only (individual piece rate) or also on a co-worker's performance (team piece rate), and (2) whether individuals have the opportunity to diversify their own idiosyncratic risk (team piece rate) or not (individual piece rate). Thus, payment based on team output carries the risk of low-productive coworkers and, thus, lower pay (e.g., Cooper, Dyck, \& Frohlich, 1992; Holmstrom, 1982; Kvaløy \& Olsen, 2006; McAffee \& McMillan, 1991), but allows the team 
members to diversify their own idiosyncratic risk (Breton, St-Amour, \& Vencatachellum, 2003; Gaynor \& Gertler, 1995), i.e. luck or subjective productivity shocks such as mood effects or other psychological aspects of motivation or distraction (Dohmen \& Falk, 2011). Individual-based pay is independent of others' performance but does not offer a diversification option. Taken together, individual payment may be more or less risky, depending on expectations about the individual's own and others' performance and the individual's own idiosyncratic risk.

The risk diversification aspect of team-based compensation has rarely been discussed in the literature, just as team incentives in general (Bandiera, Barankay, \& Rasul, 2012). Consequently, we do not know whether individuals consider risk diversification when making their sorting decision. We address this research gap and analyze whether the perceived risk of low-productive co-workers and/or the perceived idiosyncratic risk influence the sorting decision between individual- and team-based compensation. To the best of our knowledge, no previous study has analyzed the potential effects of these two risk aspects in detail. However, some studies have shown that potential teammates' productivity influences sorting between individual work and teamwork (e.g., Breton et al., 2003; Hamilton, Nickerson, \& Owan, 2003). Another strand of the literature examined risk diversification in other contexts (e.g., Bramoullé \& Kranton, 2007a; Eisenhardt \& Schoonhoven, 1996; Li \& Suen, 2000). For example, in a theoretical paper, Chiang and Mahmud (2008) analyze the optimal size of nations by considering which regions are likely to form a coalition given, among other factors, the variance in income.

To tackle the research gap regarding risk-sorting effects, we conduct a realeffort experiment consisting of nine stages: First, we measure participants' 
individual productivity levels by the number of correctly solved arithmetic tasks. Then we introduce three treatment conditions characterized by different levels of idiosyncratic risk: people are informed that at the end of the work period a given number (zero, low or high) will be added to or subtracted from the actual number of correct calculations. Then we study the sorting decision between two variable payment schemes: payment based on individual output (individual piece rate) or team output (team piece rate). In addition, we elicit participants' risk perceptions of getting matched with a low-productive co-worker. Last, we obtain participants' risk and social preferences, and individual characteristics. Our experimental design partly resembles that of Sloof and van Praag (2010), who analyze the impact of low vs. high noise in performance measurement on the provision of effort. We use the same real-effort task and integrate their operationalization of noise, i.e., idiosyncratic risk, into a multi-stage experimental design (see Dohmen \& Falk, 2011 for a similar set-up $\left.{ }^{1}\right)$.

By studying the sorting decision between individual- and team-based payments rather than between individual work and teamwork, we isolate the wage risk aspects from interfering effects such as the social desirability of teamwork, a preference for social interaction, or the impact of social ties on decision-making (Sonnemans, van Dijk, \& van Winden, 2006). In particular, team production is unaffected by intra-team spillovers and talent disparity. ${ }^{2}$ Our setting reflects particular real-life situations where economic agents can choose to share individual production risks, e.g., individual farmers in a co-op, spouses with joint accounts, or waitresses pooling tips. ${ }^{3}$

\footnotetext{
${ }^{1}$ While we analyze sorting between individual and team piece rates, Dohmen and Falk (2011) look at fixed compensation versus different variable payment schemes.

${ }^{2}$ For a different perspective, see Franck and Nüesch (2010), who find talent disparity effects in soccer.

${ }^{3}$ Of course, the diversification of idiosyncratic risks is also the main principle underlying insurance.
} 
Our experimental data support a risk diversification effect and an effect of the risk of being matched with a low-productive co-worker on sorting between individual and team piece rates. Specifically, we find perceived idiosyncratic risk relates positively to the likelihood of sorting into team piece rates. Apparently, individuals are aware of the existence of risk diversification effects under team piece rates, and opt for them whenever the idiosyncratic risk is too high. However, counterbalancing this positive effect on the attractiveness of team piece rates, we also find a negative effect of the perceived risk of being matched with a lowproductive co-worker. Given that the marginal effect of this latter risk is greater and of higher statistical significance than that of idiosyncratic risk, we suggest that concerns regarding the productivity of potential co-workers might be stronger than risk diversification considerations. We do not observe free-riding tendencies for workers who sorted into teams: Although we indeed observe lower average productivity under the team-based scheme, this is entirely due to sorting and not due to a reduction in effort, the major concern the literature focuses on.

The paper is organized as follows. In Section 1, we introduce our concepts of idiosyncratic risk and the risk of low-productivity co-workers and derive theoretical implications regarding their impact on sorting. In Section 2, we describe the experimental design and procedures. In Section 3, we present the descriptive and multivariate results. In Section 4, we conclude.

\section{Wage risk aspects of individual piece rates and team piece rates}

In most work situations, output is not exclusively determined by effort or abilities, but is also subject to some risk in the form of exogenous shocks. These shocks can be common, i.e., they affect the output of all workers equally, or idiosyncratic, i.e., each worker's output is changed by an individual productivity 
shock. A typical example of a common shock is fluctuation in demand for the good to be produced. Examples of idiosyncratic risks are one's state of health with, e.g., a cold that reduces one's productivity, or (bad) luck.

In the literature, output is often modeled as the sum of worker ability and/or effort, idiosyncratic risk, and common risk (e.g., Breton et al., 2003; Dohmen \& Falk, 2011; McAffee \& McMillan, 1991; Sloof \& van Praag, 2010). We follow this approach by defining individual output $\mathrm{x}_{\mathrm{i}}$ as:

$$
\mathrm{Xi}_{\mathrm{i}}=\pi_{\mathrm{i}}\left(\mathrm{ai}_{\mathrm{i}}, \mathrm{e}_{\mathrm{i}}\right)+\varepsilon \mathrm{i},
$$

with $\pi_{\mathrm{i}}$ as the productivity of individual $\mathrm{i}$, which is a function of individual ability $\mathrm{a}_{\mathrm{i}}$ and individual effort $\mathrm{e}_{\mathrm{i}}$, and $\varepsilon_{\mathrm{i}}$ as the individual idiosyncratic risk term. This idiosyncratic risk is assumed to have the distribution function $F$ with $\mathrm{E}[\varepsilon]=0$ and variance $\sigma^{2}$. We do not include a common risk term in our output function because the impact on the wage risk is exactly the same under individual and team piece rates and thus should not influence the sorting decision. Given this definition of individual output, we define team output as the sum of the team members' individual outputs Xi (see also Breton et al., 2003; Königstein \& Ruchala, 2007; McAffee \& McMillan, 1991).

The output risk translates into a wage risk whenever performance-based pay is given (see Dohmen \& Falk, 2011). In our case, we analyze sorting between individual piece rates and team piece rates, two performance-based pay systems. Although individual piece rates entail a variable payment per individually produced output unit, team piece rates are paid per output unit produced by any team member. For our setup, where team output is the sum of the team members' individual outputs, the assumption that every team member receives an equal share of the variable team-based pay seems justified. Thus, we have the following wage functions: 
Individual wage under the individual piece rate system: $\mathrm{Y}_{\mathrm{i}}^{\mathrm{d}}=\beta \cdot \mathrm{X}_{\mathrm{i}}$,

individual wage under the team piece rate system: $Y_{i}^{t}=\beta \cdot \frac{1}{n} \cdot \sum_{k=1}^{n} x_{k}$,

with $\beta$ as the variable pay component, $\mathrm{n}$ as the number of team members, and $\mathrm{k}$ as the index for the team members including the considered individual $\mathrm{i}^{4}$

Rationality suggests that employees choose the pay system that maximizes their utility. In our setup, an employee's utility is determined by wage $\mathrm{Y}_{\mathrm{i}}$, effort costs $c\left(e_{i}\right)$ and risk preference, where an increase in wage results in higher utility while an increase in effort costs (caused by higher effort) results in lower utility. For a given form of the utility function, which implies a certain risk preference, utility depends only on wage and effort costs. Given that effort and thus costs are deterministic (i.e., contain no risk), we can base our analysis of the relation between risks and the sorting decision on the wage functions, which enter the utility function.

Regarding risk preference, the economic literature generally assumes that employees are risk-averse (e.g., Cadsby, Song, \& Tapon, 2007). Given riskaversion, utility-maximizing employees should choose the alternative with the lower risk. ${ }^{5}$

To calculate the wage risk in our model, we refer to the commonly applied measure of risk, the variance. ${ }^{6}$ The variance of the individual piece rate (1) for individual $i$ (who knows his or her own productivity $\pi_{i}$ ) is given by:

\footnotetext{
${ }^{4}$ To simplify our analysis, we abstract from a fixed compensation component in the wage function. A fixed component of the same size for the individual and team piece rates would not affect the sorting decision. ${ }^{5}$ For risk-loving agents, the opposite holds true: they should choose the alternative with the highest risk.

${ }^{6} \mathrm{We}$ thank an anonymous referee for pointing out that theoretically the variance is not the best measure of increasing risk (see Rothschild \& Stiglitz, 1970) and that mean-variance analysis, which we basically apply here, is consistent with expected utility maximization only under rather specific assumptions (see e.g. Baron, 1979). While we share these concerns in general, in this specific case we feel justified in applying the simpler reduced form approach because we can show that it is consistent with maximization of expected utility when assuming a common CARA utility function. The corresponding math is available from the authors upon request.
} 


$$
\operatorname{Var}\left(Y_{i}^{d}\right)=\operatorname{Var}\left(\beta \cdot\left(\pi_{i}\left(a_{i}, e_{i}\right)+\varepsilon_{i}\right)\right)=\beta^{2} \operatorname{Var}\left(\varepsilon_{i}\right)=\beta^{2} \cdot \sigma^{2}
$$

Clearly the only wage risk under individual piece rates is the idiosyncratic risk $\sigma^{2}$. All other parts of the wage function (1) are known to employee $i$ and thus deterministic.

Assuming that idiosyncratic risk terms $\varepsilon_{k}$ are iid and are independent from productivity $\pi_{k}$ of potential co-workers, the variance of the team piece rate (2) for the individual $i$ is:

$$
\begin{aligned}
\operatorname{Var}\left(Y_{i}^{t}\right)=\operatorname{Var} & \left(\frac{\beta}{n} \cdot\left(\pi_{i}\left(a_{i}, e_{i}\right)+\varepsilon_{i}+\sum_{k=1}^{n-1}\left(\pi_{k}\left(a_{k}, e_{k}\right)+\varepsilon_{k}\right)\right)\right) \\
& =\frac{\beta^{2}}{n^{2}}\left(\operatorname{Var}\left(\varepsilon_{i}\right)+(n-1)\left(\operatorname{Var}\left(\pi_{k}\right)+\operatorname{Var}\left(\varepsilon_{k}\right)\right)\right) \\
& =\frac{\beta^{2}}{n^{2}}\left(n \cdot \sigma^{2}+(n-1) \cdot \operatorname{Var}\left(\pi_{k}\right)\right) \\
& =\frac{\beta^{2}}{n} \cdot \sigma^{2}+\frac{\beta^{2} \cdot(n-1)}{n^{2}} \operatorname{Var}\left(\pi_{k}\right) .
\end{aligned}
$$

This shows that under the team piece rate system, the inherent wage risk is affected not only by the idiosyncratic risk aspect $\sigma^{2}$ but also by the variance in productivity of potential co-workers $\operatorname{Var}\left(\pi_{k}\right)$. The higher this variance $\operatorname{Var}\left(\pi_{k}\right)$, the higher the expected difference between an individual's own productivity and that of the individual's team members. Given the concavity of the utility function of a risk-averse individual and the implied decreasing marginal returns, downward deviations from one's own productivity are weighted much more heavily than upward deviations. This is why the meaning of the variance $\operatorname{Var}\left(\pi_{k}\right)$ for decision makers lies mainly in being matched with someone of lower productivity. The higher the downward deviation from an individual's own productivity, the lower the team output, which results in a lower payoff compared to being paid based solely on one's own output. This risk aspect, inherent in all team-based 
compensation schemes, has received much attention in the literature as causal for a low preference for teamwork among highly productive employees (e.g., Breton et al., 2003). ${ }^{7}$

Although this additional risk $\operatorname{Var}\left(\pi_{k}\right)$ should induce risk-averse employees to sort into the individual piece rate scheme, team piece rates might also be more attractive to risk-averse employees because the rates allow for the diversification of idiosyncratic risks $\sigma^{2}$ (e.g., Bramoullé \& Kranton, 2007b). The idea of risk diversification is that a portfolio of uncorrelated risky assets is subject to less variation than an arbitrary risky asset. In the context of our sorting decision, team output is subject to less variation due to exogenous shocks than individual output. The intuition for this result is that on a team, the negative idiosyncratic shock of one team member might be compensated for by the positive idiosyncratic shock of another team member. Consequently, although a higher idiosyncratic risk $\sigma^{2}$ translates directly into a riskier wage under the individual piece rate system, risk diversification under the team piece rate scheme - as modeled by division by n (see equation 4 compared to equation 3) — can suppress the effect of an increase in idiosyncratic risk. This option of diversifying idiosyncratic risk should therefore render team piece rates more attractive from a risk perspective.

Thus, we consider two opposite risk aspects that determine the risk associated with team-based pay compared with individual piece rates: On the one hand, the total risk under a team piece rate could be perceived as higher because an individual's wage depends not only on the individual's own productivity but also on unknown co-workers' abilities and efforts. On the other hand, team piece rates

\footnotetext{
${ }^{7}$ Of course the individual with the lowest possible productivity does not need to fear being matched with someone of even lower productivity. However, the sorting behavior of the least productive individual is still driven by this risk aspect if the individual is not aware that he or she is the least productive.
} 
allow for diversification of idiosyncratic wage risks so that the perceived wage risk could be lower for team piece rates.

As the individual perceptions of these two risk aspects may be relevant for the sorting decision, we pose the following hypotheses:

H1: Ceteris paribus, the higher the perceived risk regarding co-workers' productivity, the less likely a risk-averse individual will sort into the team piece rate scheme instead of the individual piece rate scheme.

$\mathrm{H} 2$ : Ceteris paribus, the higher the perceived idiosyncratic risk, the more likely a risk-averse individual will sort into the team piece rate scheme instead of the individual piece rate scheme.

Given that these two aspects are opposed, the more attractive alternative from a risk perspective depends on the relation of these two risk aspects, or more specifically, their effects. However, it is not clear whether both risk-sorting effects can be found empirically and if so, whether one effect dominates the other.

\section{Experimental design and procedures}

The question of whether both risk aspects influence individual behavior is difficult to investigate in the field due to a lack of data. To study factors that drive people's sorting decision between individual- and team-based piece rates, the payment schemes must differ only in terms of monetary incentives. In particular, we have to rule out that non-monetary incentives reflecting the intrinsic value of teamwork drive the sorting decision. In the field, various incentives (e.g., monetary and non-monetary, or implicit and explicit incentives) typically coincide and make it difficult to separate clean effects. In addition, idiosyncratic risks are 
often neither observable nor can they be exogenously varied. Similarly, the observability of individual preferences and relative self-assessments is typically not given, and individual performance is often not perfectly measurable in the field.

Thus, we implement a controlled laboratory experiment that includes a realeffort work task of repeatedly adding three two-digit numbers. ${ }^{8}$ The setting provides an experimental environment that resembles real work (Van Dijk, Sonnemans, \& van Winden, 2001; Ivanova-Stenzel \& Kübler, 2011) and allows us to observe a sufficient degree of output heterogeneity. Furthermore, by permitting participants to alternatively spend their work time performing a leisure activity (e.g., reading, listening to music), we explicitly create an opportunity cost for working and thus facilitate shirking. Figure 1 shows how the arithmetic problems are presented on a computer screen. If participants click the OK button, a new problem appears instantly. All participants are shown the same sequence of problems. Feedback on the number of (correct) answers is given only at the end of the work period.

Fig. 1 Presentation of the arithmetic problems -Insert Figure 1 here -

The experiment consists of nine stages (see Table 1). In stage 1, we measure individuals' productivity by the number of arithmetic problems correctly solved within five minutes. Participants are paid a piece rate of 30 points per correct answer. In stage 2, we explain the decision task to the participants. They are

\footnotetext{
${ }^{8}$ This task is commonly applied (e.g., Eriksson, Poulsen, \& Villeval, 2009, Niederle \& Vesterlund, 2007, Sloof \& van Praag, 2010). Simple arithmetic tasks have previously been described as being easy to explain, no particular requirements are needed, and they allow the observation of a sufficient degree of performance heterogeneity (Dohmen \& Falk, 2011). In addition, arithmetic tasks are seen as a relative good proxy for cognitive ability. Strong learning effects during the experiment are not expected.
} 
informed that they will solve arithmetic tasks similar to the ones before and that they will be given 30 minutes to do the work. Then, participants are told that they have a choice between an individual piece rate and a team piece rate as payment schemes. If the participants choose the individual piece rate, they are paid 30 points per correct answer. If the participants choose the team piece rate, they are randomly and anonymously matched with another participant who has chosen the same payment scheme. ${ }^{9}$ The team piece rate equals 15 points per calculation that team member 1 or 2 solved correctly. That is, we implement an equal sharing rule in the team condition. To ensure that the participants have a clear grasp of how their productivity and risks and those of other team members translate into team output, we use the minimal team size of two. Note that the participants stay on the same team until the work period is over and that they will never know with whom they have been matched.

- Insert Table 1 about here -

Independent of the outcome of the sorting decision, participants receive an additional flat wage of 4050 points to avoid losses. Before the sorting decision, participants are informed about the volatility of their work environment. We follow Sloof and van Praag (2010) in implementing external shocks, i.e., our idiosyncratic risk, via noisy individual performance measurement: When calculating a participant's payoff, the number of correct calculations is not registered perfectly. In particular, there is a 50 percent chance that an additional number of correct calculations is added to the actual number of correct

\footnotetext{
${ }^{9}$ If an uneven number of participants choose the team piece rate, one participant is matched twice but receives payment from only one team.
} 
calculations. However, there is also an equal probability that the participant is unlucky and the same number is subtracted. As a treatment variation, we implement a large shock (+/- 135 calculations), a small shock (+/- 10 calculations), and a no shock environment. We assume that the size of the shock has an impact on the participants' perceived idiosyncratic risk, which in turn is expected to have an impact on the sorting decision. We carefully explain to the participants that the chosen contract determines how they are paid for the produced output and that their decision is irrevocable. At the end of this stage, the actual sorting decision takes place (stage 3). Additionally, we ask participants to indicate the strength of their preference for either individual- or team-based pay on an 11-point scale ranging from "definitively prefer individual piece rates" to “definitively prefer team piece rates." In doing so, we receive additional information on individuals' sorting preference, making it, for example, possible to discriminate between those who are rather indifferent about the two options and those who hold a strong preference for either option.

In stage 4, we elicit the participants' perception of the riskiness of the situation. In both shock treatments, the workers' wage is partly determined by ability and effort and partly by chance. The larger the shock $\sigma$ (i.e., the number of added or subtracted calculations), the higher the individual idiosyncratic risk. However, as only the perceived riskiness of a situation can be behaviorally relevant, we ask participants to evaluate the degree of control they have over the outcome of the forthcoming work situation (Wehrung, Lee, Tse, \& Vertinsky, 1989). The participants could react on an 8-point scale, ranging from "complete control" $(=1)$ to "no control at all" (=8). Furthermore, participants evaluate how they perceive the situation regarding the number of registered correctly solved questions ranging from "very risky" (=1) to "not risky at all" (=8). 
In stage 5, participants estimate their relative performance. We ask "What do you think: Which percentage of participants will solve more arithmetic tasks correctly than you?" Participants can enter any number between zero and 100 . Participants are paid 100 points for a correct estimation and 50 points if the estimate deviates by less than 10 . The relative self-assessment measure is intended to catch expectations about an individual's own and others' abilities and efforts (i.e., shirking behavior). Therefore, the relative self-assessment measure is an implicit measure of the risk of being matched with a low-productive co-worker.

In stage 6, participants solve arithmetic problems for 30 minutes or pursue leisure activities.

After the 30 minutes of work time, the idiosyncratic shock is randomly drawn, by rotating a pointer over a white and red disk (Sloof \& van Praag, 2010). Each color fills half the disk. A random device stops the pointer. If this happens in the white area, the participant is lucky and a given number $\sigma$ is added to the actual number of correct calculations. Otherwise a given number $\sigma$ is subtracted.

In the remaining three stages, we elicit participants' preferences and personal characteristics as they have previously been shown to matter in comparable decision situations (Dohmen \& Falk, 2011). Stage 7 measures individuals' risk preferences using a lottery mechanism (Holt \& Laury, 2002). ${ }^{10}$ Participants are shown a table with 10 rows and have to choose between a safe lottery and a risky lottery for each row. Counting the number of safe choices yields a measurement of risk aversion. One row is randomly chosen and paid accordingly. In stage 8 , we measure participants' social preferences with the decomposed game technique (Griesinger \& Livingston, 1973; Liebrand, 1984). Participants choose repeatedly

\footnotetext{
${ }^{10}$ Dave, Eckel, Johnson, and Rojas (2010) argue that this measure is rather complex, which could bias the elicited risk preference for participants with low mathematical skills. However, we do not find the implied correlation of risk preference and mathematical skills in our data.
} 
between two "own-other" payoff combinations, which assign a certain amount of (hypothetical) money to the players. The method allows us to distinguish between individuals endowed with social preferences (“cooperators") and other types (“individualists", "competitors"). ${ }^{11}$

Stage 9 gathers socio-demographic data on age, nationality, gender, major, and number and gender of siblings. Participants also complete a 15-items (Germanlanguage) version (Gerlitz \& Schupp, 2005) of the well-established NEO-FFI by Costa and McCrae (1989), a personality questionnaire indicating individuals' five main personality dimensions (the so-called Big Five: conscientiousness, neuroticism, openness to experience, agreeableness and extroversion).

The experiment, conducted at the TrEx laboratory at the University of Trier, was programmed in z-Tree (Fischbacher 2007), and participants were recruited using ORSEE (Greiner 2004). Overall, 82 participants (38 percent males) participated in the three treatments. The participants received 3 cent (1000 points $=€ 1)$ per correct calculation, a base salary of $€ 4.05$, up to $€ 3.85$ in the lottery task and a show-up fee of $€ 2.50$. On average, participants earned about $€ 16$, and sessions lasted less than 1.5 hours.

\section{Results}

3.1. Sorting decision between individual piece rates and team piece rates

\subsubsection{Descriptives}

About 70 (68) percent of (risk-averse) participants chose the individual piece rate. In the following, we try to identify determinants that influence individuals' sorting decisions. First, we consider the perceived risk regarding co-worker

\footnotetext{
${ }^{11}$ We run stages 7 and 8 after the sorting decision and work phase to prevent endowment effects resulting from stage 7 and a focus on social considerations (stage 8) from biasing our main constructs. Of course, thus we put up with prior stages affecting our measures in stages 7 and 8 .
} 
productivity. We measure this kind of risk via the estimated percentage of participants who will answer fewer questions correctly than the considered individual. The perceived risk ranges from 15 to 100 with an average of 67.88 . Comparing the perceived risk to the actual risk, i.e., the percentage of participants who earned fewer points in the first stage, we find that participants overestimate the risk by 18.46 percentage points on average. This bias in perceived risk could lead some participants to choose the individual piece rate even though they should have chosen the team piece rate.

Second, we test whether participants' perception of idiosyncratic risk is affected by the noise treatments. Perceived idiosyncratic risk is measured via an 8-point Likert scale, asking for the level of control people feel they have over the outcome ( $8=$ "no control at all"). We find highly significant treatment effects: the average score ranges from 2.48 in the no shock treatment to 4.27 in the low shock condition up to 5.00 in the high shock condition. The difference is significant $(p<.001)$ using a Kruskal-Wallis test. Thus, we conclude that the noise variation is reflected in participants' perception of individual idiosyncratic risk.

To verify that the observed differences in perceived idiosyncratic risk stem from treatment variation rather than from participants' heterogeneity, we test for potential subject pool effects. Table 2 shows that the three treatment groups do not differ significantly regarding productivity, risk and social preferences, personality, and basic demographics (age, major and gender) using a Kruskal-Wallis test (all $p$-values >.05)

- Insert Table 2 about here - 


\subsubsection{Multivariate Results}

To test our hypotheses, we run a logistic regression (with robust standard errors) of the sorting decision on our perceived risk measures and controls. Given that our theoretical predictions hold only for risk-averse individuals, we run the estimation with only the risk-averse ${ }^{12}$ observations, i.e., 73 percent of our participants. We control for the degree of risk aversion to see whether we find the strength of the risk preference has an effect on sorting. As ability has been shown to influence the sorting decision between individual work and teamwork (e.g., Grossman, 2004; Hamilton et al., 2003; Kocher, Strauß, \& Sutter, 2006;

Königstein \& Ruchala, 2007), we include our productivity measure (number of correctly solved arithmetic problems in stage 1) in the regression. Furthermore, we control for social preferences, major (economics or not), and gender.

Given that our dependent variable is a dummy variable taking the value of 1 whenever the team piece rate was chosen, logistic regression is suitable. Table 3 presents the average marginal effects of the explanatory and control variables on the likelihood of choosing the team piece rate system. Given our coding of the dependent variable, positive marginal effects demonstrate that an increase in the corresponding variable increases the likelihood of sorting into the team piece rate.

- Insert Table 3 about here -

Supporting hypothesis 1, we find the risk regarding co-workers' productivity has a significant negative effect on the likelihood of sorting into the team piece

\footnotetext{
${ }^{12}$ For risk-loving individuals, the expected effects of our risk variables on the sorting decision should be the exact opposite. Risk-neutral individuals should not take risks into account at all. In principle, we could test whether the effects are indeed the exact opposite for risk-averse and risk-loving individuals. However, only seven of 82 observations are risk-loving and all opted for individual piece rates, so that an estimation of the full sample with dummy variables for different risk preferences is not feasible.
} 
rate. This result suggests that risk-averse individuals try to avoid the risk of being matched with a low-productive co-worker and therefore choose the individual piece rate. This direct empirical evidence is in line with common intuition suggesting that relatively high-productive workers reject team compensation. In accordance with hypothesis 2 , Table 3 also shows a significant positive relation between perceived idiosyncratic risk and the likelihood of sorting into team piece rates. This effect can be explained with the possibility of diversifying one's own idiosyncratic risk when entering the team piece rate scheme.

To be able to suggest which risk effect is stronger and might overcompensate the other, we z-standardized the two risk measures. This allows us to compare the size of the average marginal effects of the two risk aspects. Given that the coefficient of the risk regarding co-workers' productivity is larger and of higher statistical significance, we suggest that when deciding whether to work under an individual piece rate or a team piece rate, concerns regarding the productivity of potential co-workers might be stronger than risk diversification considerations.

In contrast to the existing literature (e.g., Grossman, 2004; Hamilton et al., 2003; Kocher et al., 2006; Königstein \& Ruchala, 2007), we do not find an effect of individual productivity on the sorting decision. However, this lack of significance is likely due to productivity being indirectly incorporated in our measure of the risk of being matched with someone who has lower productivity than oneself. Our data support this explanation of the lack of a significant productivity effect: If we omit this risk measure from the estimation, productivity has a significant and negative effect on the likelihood of sorting into team piece rates. Given that the absolute level of productivity is not significant when we include a relative measure, it seems that not absolute but relative productivity is decisive. 
Regarding our control variables, we observe no significant effects. Although the amount of perceived risk is relevant, the degree of risk aversion has no significant effect on the sorting decision. Similarly, individuals' willingness to cooperate, an economics major, and gender do not have significant impacts on the sorting decision.

\subsubsection{Robustness Checks}

To check the robustness of our results, we run the same estimation as in Table 3 with the full sample, i.e., including the risk-neutral and risk-loving participants (see Table 4, column 1). Our results remain qualitatively the same, which was to be expected as the majority of individuals are risk-averse.

- Insert Table 4 about here -

As another robustness check, we apply a different dependent variable in the form of the strength of the preference for the chosen compensation scheme. We run an OLS estimation with robust standard errors of this quasi-metric variable on our explanatory and control variables (column 2). Our results remain qualitatively unchanged with the exception of the degree of risk aversion, which is now significant and negative at the 10-percent level. This implies that highly riskaverse participants have a stronger preference for individual piece rate schemes.

As an alternative to the perceived idiosyncratic risk measure used in Table 3, we asked how risky participants judged the situation to be regarding the registered number of correctly solved tasks. We find the same qualitative effects of our risk variables as before (column 3) and our control variables remain insignificant. 
Last, we include measures for the Big Five personality traits in our estimation because personality has recently been shown to influence sorting decisions (Dohmen \& Falk, 2011) and could be correlated with risk preference (Borghans, Duckworth, Heckman, \& ter Weel, 2008). Our results are mainly robust to including these additional controls (see column 4); however, our idiosyncratic risk measure just misses significance at the 10-percent level. Conscientiousness has a significant and negative impact on the likelihood of sorting into team piece rates, whereas the other personality traits have no effect.

\subsection{Productivity under individual and team piece rates}

When productivity before and after the sorting decision is compared, the productivity difference can be due to a) learning or exhaustion or b) changes in effort due to a different incentive scheme. Note that there is no change in the incentive scheme for participants who sorted into individual piece rates. Consequently, differences in productivity are likely caused by learning or exhaustion.

Figure 2 compares average productivity before and after the sorting decision for participants who sorted into individual piece rates (the first cluster of three bars) and those who opted for team piece rates (the second cluster). The third bar of each cluster displays the productivity after the sorting decision normalized to a five-minute interval, allowing for level comparison with productivity before the sorting decision.

Fig. 2 Productivity before and after sorting decision

- Insert Figure 2 about here - 
Regarding the question of how productivity changes between the two work stages, we first look at the first cluster and compare the productivity before sorting with the normalized productivity after sorting in the individual piece rate scheme. We observe higher (normalized) productivity after (27.84) compared to before the sorting decision (24.83). The difference is highly significant $(p<.001)$ using a twosided Wilcoxon signed-rank test. The increased productivity is likely caused by learning effects that outpace potential exhaustion effects.

Working under a team piece rate compared to individual piece rates holds the option of free-riding on co-workers' productivity. If free-riding is an issue, we would expect to see a decrease in efforts from the first work stage under individual piece rates to the second work stage for individuals who sorted into team piece rates (the second cluster). However, when comparing the respective productivity figures, we find a productivity increase of about the same magnitude as for individual piece rates. In the work stage before the sorting decision, participants show average productivity of 18.67 correctly solved arithmetic problems. In the second work stage, the normalized average productivity for these participants was 21.77. Again, this difference is significant using a two-sided Wilcoxon signed-rank test ( $p=.002)$. The observations together reinforce the conclusion that individuals who opted for team-based compensation did not do so to free-ride on others' performance. As we observe productivity increases of the same magnitude under both payment schemes, the incentive scheme is likely to have no (strong) effect on productivity differences. Rather, learning effects may occur and positively influence participants' abilities.

In line with previous findings (e.g., Dohmen \& Falk, 2011), Figure 2 shows ample evidence of productivity sorting. A comparison of the first bar in both clusters reveals that individuals who sorted into individual piece rates were more 
productive (24.83) than those who opted for the team piece rate (18.67) according to the stage 1 productivity indicator. This difference is significant with $p=.014$ using a two-sided Mann-Whitney test. Thus, we can conclude that highproductive workers prefer to get paid based on their own achievements, whereas low-productive workers prefer a team piece rate. This is in line with some previous findings (e.g., Kocher et al., 2006, but not Hamilton et al., 2003). The ex-ante productivity difference (which was due to sorting as shown before) continues in the subsequent work phase. A similar statistical difference results when looking at the productivity and the normalized productivity in the second work phase between participants who sorted into individual and team piece rate $(p=.022)$.

Apart from the chosen incentive system, the treatment in the form of an exogenous productivity shock (increasing or decreasing individual output) could also influence participants' effort provision. In an experiment, Sloof and van Praag (2010) find that efforts are significantly higher in the high than in the low shock environment. Remember that in our experiment, we have three treatments with large, small and no productivity shock. Figure 3 shows for each treatment the respective average productivity in the second work stage (where we can observe the effects of a shock) for individuals who sorted into individual piece rates (the first cluster) and those who chose the team piece rate (the second cluster).

Fig. 3 Productivity after sorting decision depending on treatment -Insert Figure 3 about here-

When comparing productivity between treatments and within the chosen incentive scheme, the Kruskal-Wallis test (two-sided) demonstrates that productivity differs significantly among shock treatments in the individual piece 
rate scheme $(p=.016)$ but not in the team piece rate scheme $(p=.212)$. A closer look at the individual piece rate scheme using Mann-Whitney tests reveals that productivity in the large shock treatment is significantly higher than in the small shock treatment $(p=.005)$ and the no shock treatment $(p=.030)$. However, the difference between the no shock treatment and the small shock treatment is not significant $(p=.988)$.

To verify that the difference between the small and large shock treatment does not stem from subject pool effects, we compare productivity indicators between treatments. As expected, we find that no significant difference exists (KruskalWallis test, $p=.114$ ), indicating that the observed differences in the 30-minute work phase do not result from exogenous productivity differences within the treatment groups. Instead, we may conclude that—in line with Sloof and van Praag (2010) - a high shock induces high effort. On top of that, we derive the following results: First, the effort-enhancing effect of noise is present only in the individual piece rate scheme. For team-based pay, we find qualitatively similar results, but the difference is not statistically significant. Second, our data show that people in our between-subject design exert similar effort levels in the no shock condition and the low shock condition under both payment schemes. Thus, we conclude that low shock environments are inefficient and completely comparable to environments where no shock happens at all. Or, differently phrased, the existence of small noise in performance measurement does not stimulate effort exertion compared to perfect performance measurement. 


\section{Conclusion}

This paper advances the research on multidimensional sorting by focusing on two different variable pay contracts, individual and team piece rates. Earnings from both schemes are uncertain and therefore risky, but imply different wage risks: Team piece rates carry the risk of being matched with low-productive coworkers but allow individuals to diversify the own idiosyncratic risk. These features are not present under individual piece rates.

Although there is ample evidence that individuals consider the risk of lowproductive co-workers, the risk diversification aspect has mostly been neglected in the literature. Our analysis shows that both risk aspects help explain sorting, but considerations concerning the risk of being matched with a low-productive coworker seem to be more important than risk diversification considerations. Specifically, we find that perceived idiosyncratic risk positively relates to the likelihood of sorting into team piece rates. Apparently, individuals are aware of the existence of risk diversification effects under team piece rates and opt for them whenever the idiosyncratic risk gets too high. However, counterbalancing this positive effect on the attractiveness of team piece rates, individuals also consider the risk of being matched with a low-productive co-worker when choosing team piece rates. We find a significant and negative relation between the estimated percentage of potential co-workers with lower productivity than one's own and the likelihood of opting for team piece rates. Given that the marginal effect of this latter risk is greater than that of idiosyncratic risk, we tentatively conclude that although risk diversification is a driver of risk-sorting decisions, the risk of being matched with a low-productive co-worker carries more weight. 
A potential reason for this finding might be that participants are more willing to bear exogenous variations in income due to an act of nature than others' intentional choices. Indeed, research on the effects of causal attributions on preferences (Blount, 1995; Charness, 2004) has shown that individuals have a need to assign responsibility for why outcomes occur. In particular, there might be a tendency to assign blame to co-workers for free-riding, i.e., exerting low effort and/or for choosing team compensation while knowing that one's own ability is low. Furthermore, the result could in part be driven by our choice of a team size of two. In larger teams, risk diversification possibilities are greater, and therefore, the diversification effect on the sorting decision should be stronger. Although this might lead us to reverse our conclusion regarding the strength of the effect, it does not affect our main result of finding evidence for both risk effects.

Although common intuition and some of the literature suggest that team-based compensation induces individuals to reduce their effort, we find no such effect. Instead, there is strong evidence that low-productive workers tend to choose teambased payment, whereas high-productive individuals prefer to be paid based on their own achievements. Thus, when self-selecting into team piece rates, the risk of being matched with a low-productive co-worker is real due to negative selection.

Our sorting analysis also shows that, unlike most of the literature claims (e.g., Kocher et al., 2006; Königstein \& Ruchala, 2007), not absolute productivity but one's productivity in relation to the expected productivity of potential co-workers is decisive in the sorting decision. In the absence of a relative measure, absolute ability significantly predicts the sorting decision. However, once we add a relative measure of productivity, this measure becomes decisive. In line with intuition, this 
implies that individuals' decision to sort into a team depends crucially on their expectations about potential co-workers' performance.

\section{Appendix}

\section{Experimental Instructions}

\section{General Instructions}

Thank you for participating in this economic decisions experiment. If you read the following instructions carefully, you can - depending on your decisions and those of the other players - earn further sums of money in addition to your 2.50 Euros for showing up on time.

During the experiment we will not speak of Euros, but of points. At the end of the experiment, the points will be converted into Euros at the following rate:

10 Points $=1$ Cent

At the end of the experiment, the sums of money you will have earned given your decisions will be paid to you in cash.

The experiment consists of $\mathbf{4}$ stages and a questionnaire. Every stage begins with a detailed explanation. The details will appear on the computer screen under the heading "Instructions." Please read these instructions carefully. If you have any questions, please raise your hand and we will come to you.

In this experiment, we will ask you - among other things - to do additions. The exercises require mental arithmetic, which means that no mathematical aids, i.e., calculators, mobile phones, or calculations on scrap paper are allowed. If you disregard these rules, you will be excluded from the experiment, and you will receive no pay.

During the experiment, you will not be allowed to communicate with other participants. Furthermore, we would like to point out that the computer is to be used only for the experiment. Communication between participants and unauthorized use of the computer will lead to exclusion from the experiment.

\section{Instructions for Stage 1}

In this part, it is your job to solve addition problems. In the process you will add three two-digit numbers (for example: $23+43+10$ ). Once you have found the answer, please enter it in the corresponding box and click the OK button with the mouse. You can earn money by answering the addition problems. For every correctly answered problem you receive 30 points. During a 5-minute period, you can answer as many problems as you like.

Below you will see an example of an entry form. Directly under your addition problem, you will see the entry box for "your answer" and the OK button. If you enter the correct number and verify it with OK, you will receive 30 points, and the computer will immediately generate a new addition problem from random 
numbers. If the number entered and verified with $\mathrm{OK}$ is incorrect, you will receive 0 points for this problem, and likewise, a new addition problem will immediately be generated. At the end of the 5-minute period, you will be informed how many addition problems you answered correctly and how many points you earned. Please calculate the answer for the example problem below, enter the answer in the entry box, and click the OK button with the mouse.

Add the values A, B, and C:

Value A: $\quad 23$

Value B: $\quad 43$

Value C: $\quad 10$

Your answer:

As a reminder: For every addition problem that you answer correctly, you will receive 30 points. During the 5-minute period, you can answer as many questions as you like. In the upper right corner of the screen, the remaining time in seconds is shown. Please press Start as soon as you are ready to start with the addition problems.

Screen for the 5-minute work phase

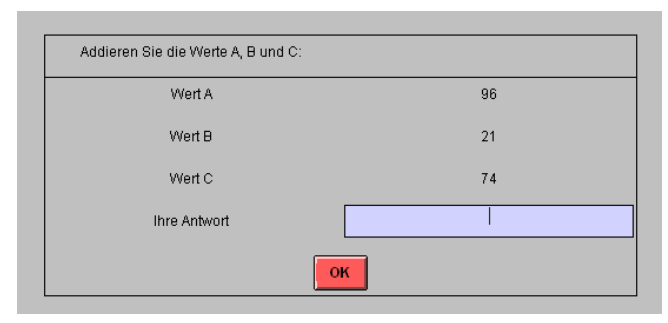

Hint: Enter your answer and confirm your entry by clicking the OK button. The next problem will appear instantly. You receive 30 points for every addition problem that you answer correctly.

\section{Instructions for Stage 2}

In the next stage, you have 30 minutes to answer as many additions problem as you like. The remaining time is shown in the upper right corner of the screen. Again, in this stage, you can earn money. You will receive a fixed amount of 4,050 points for this 30-minute stage. In addition, you will receive a certain number of points for every correctly answered addition problem. For this variable payment, you can choose among the following two alternatives.

Alternative A:

You will be randomly paired with another participant, who has also chosen this payment option. You will not find out who you have been paired with. Your earnings depend not only on the number of addition problems that you have answered correctly, but also on the number of addition problems that the other 
participant has answered correctly. Likewise, the other participant's result depends on your results. For every correctly solved problem, both participants will receive 15 points each, independent of who solved the problem correctly. If, for example, you solve one problem correctly and the other participant solves two problems correctly, then a total of three addition problems were answered correctly, and you will receive, just as the other participant, $3 \times 15$ points $=45$ points. If you solve zero problems correctly and the other participant solves 10 problems correctly, you both receive 150 points each.

\section{Alternative B:}

In this pay alternative, only your own results determine how much you earn. For every correctly answered addition problem, you receive 30 points. If you, for example, solve three problems correctly, then you receive $3 \times 30$ points $=90$ points. If you answer zero problems correctly, you receive 0 points.

Independent of the chosen pay alternative, you receive a fixed amount of 4,050 points. This fixed amount will be paid to you independent of the number of correctly answered problems.

Before you are credited the points for the number of correctly answered problems, a random draw will decide for every individual participant whether for this person 10 correct addition problems are added to or deducted from the total. Both outcomes of the draw are equally likely. You will be paid based on the modified number of correctly answered problems and corresponding to your chosen pay alternative $\mathrm{A}$ or $\mathrm{B}$.

The following examples illustrate this for pay alternatives A and B:

Example 1: Participant 1 solved 160 problems correctly; participant 2 solved 110 problems correctly. The random draw results in participant 1 receiving 10 additional correctly answered problems and deducting 10 correctly answered problems from participant 2. Correspondingly, participant 1 has 170 correctly answered problems and participant 2 has 100.

Alternative A:

Both participants receive $170 \times 15$ points $+100 \times 15$ points $=4,050$ points.

Alternative B:

Participant 1 receives $170 \times 30$ points $=5,100$ points. Participant 2 receives $100 \times 30=3,000$ points.

Example 2: Participant 1 solved 90 problems correctly; participant 2 solved 150 problems correctly. The random draw results in a deduction of 10 correctly answered problems from each participant. Correspondingly, participant 1 has 80 correctly answered problems, and participant 2 has 140 .

Alternative A:

Both participants receive $80 \times 15$ points $+140 \times 15$ points $=3,300$ points.

Alternative B:

Participant 1 receives $80 \times 30$ points $=2,400$ points. Participant 2 receives $140 \times 30$ points $=4,200$ points. 


\section{Instructions for Stage 3}

Please note:

The addition problems, which you are given in the next 30 minutes, are of the same type as the ones you previously answered. Again, you have to add three twodigit numbers. The numbers are generated randomly. Consequently, the problems be answered differ neither in their level of difficulty nor in any other characteristic between pay alternatives A and B. Also note that you can choose your own work speed. You can work fast, slow, or not at all. You can also choose to keep yourself occupied with other activities. For example, in the 30-minute period, you can read a book, a journal, or newspaper that you brought, or you can listen to music on a MP3 player, or do anything else that you wish. However, you may not use a calculator or a cell phone, and you may use the computer only for the experiment. That means that you are not allowed to close the experimental program and cannot use the Internet or other applications. Furthermore, you may not communicate with other participants or leave the experimental laboratory. Apart from these restrictions, you can spend the 30 minutes however you like.

Please make a decision: Which pay alternative do you choose?

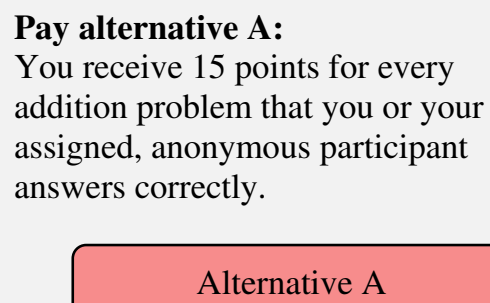

\section{Pay alternative B:}

You receive 30 points for every addition problem that you answer correctly.

\section{Alternative B}

The 30-minute phase will begin shortly, in which you can earn additional money by solving addition problems. For this phase, you can choose between being compensated according to pay alternative A (you receive 15 points for every addition problem that you or your assigned, anonymous participant answers correctly) and pay alternative B (you receive 30 points for every addition problem that you correctly answer). Please use the 11-point scale below to indicate how strong your preference for your chosen pay alternative is. By choosing one of the two outer boxes, you indicate that you explicitly prefer pay alternative A or B. With the values in between, you can grade your choice.

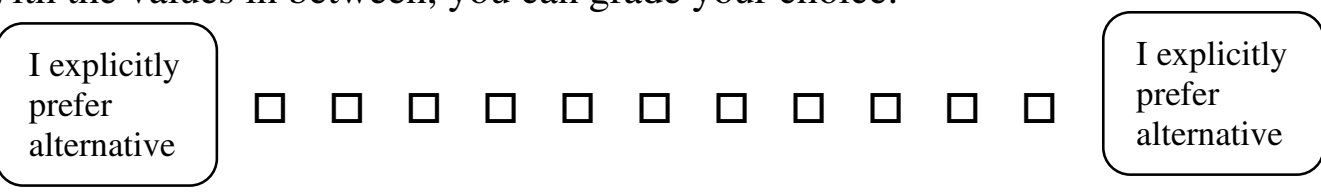

\section{Instructions for Stage 4}

Please answer the following questions:

How do you perceive the 30 -minute work phase? 
Situation is very

Situation is not risky regarding the number of

registered questions risky regarding the number of registered questions

I have complete I have no control at control over the outcome of the all over the situation outcome of the situation

\section{Instructions for Stage 5}

\section{What do you think: What percentage of participants will solve more questions correctly than you?}

Your payment is higher the closer your guess is to the exact percentage. If you guess the exact percentage, you receive 100 points. If your estimate is within 10 percentage points above or below the correct number, you receive 50 points. If your estimate deviates by more than 10 percentage points, you receive 0 points in this stage.

Please enter the percentage points as follows: For a probability of $64 \%$, enter "64". For a probability of $2 \%$, enter " 2 ". Please enter only whole percentage points (no decimal places).

What percentage of participants - according to you estimation-will solve more addition problems correctly than you?

Your answer:

\section{Instructions for Stage 6}

Example screen for the work phase

Add the values $\mathrm{A}, \mathrm{B}$, and $\mathrm{C}$ :

Value A: $\quad 68$

Value B: $\quad 99$

Value C: $\quad 14$

Your answer:

\section{OK}

Hint:

You are working under pay alternative B. As a reminder: Pay alternative B implies that you receive 30 points for every addition problem that you correctly answer. 


\section{Example screens for idiosyncratic risk}

\section{Screen 1:}

You have chosen pay alternative B.

You answered a total of 5 problems correctly. Therefore, you would receive 150 points. Now a random draw will determine if 10 correctly answered problems will be added to or subtracted from your total. The random draw is visualized with the help of a "clock". You will see this clock on the next screen. It is simply a circle split into four equally sized, colored parts. Two of the parts are white, and two parts are red. The clock also has one clock hand. This hand rotates clockwise until the computer stops the clock after a random period.

If the hand stops in a white area, 10 correctly answered addition problems will be added to your total of correctly answered problems. If the hand stops in a red area, 10 correctly answered addition problems will be subtracted. Because the areas are the same size, each result has the same probability.

\section{Screen 2:}

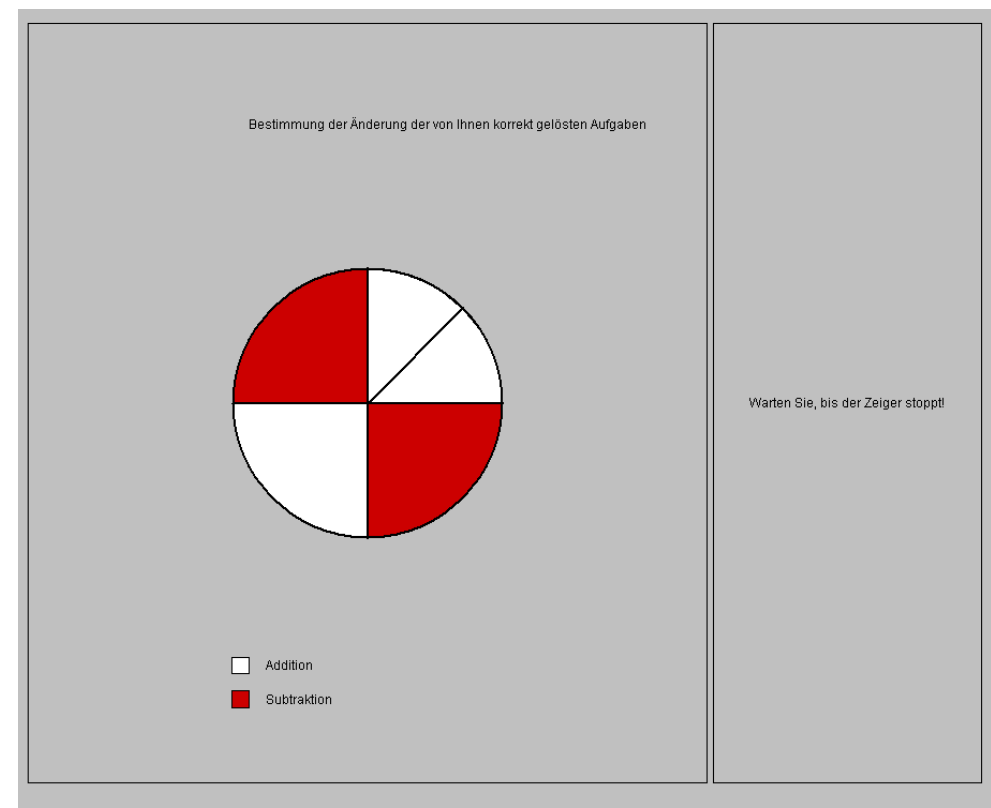

Random draw of the change in your correctly answered problems.

Wait until the hand stops!

\section{Screen 3:}

The random draw that changes the number of your registered correctly answered problems stopped in a white area. That means that 10 correctly answered problems will be added to your total.

Summary

Number of your correctly answered addition problems: 5

Change: 10

Total number of registered addition problems: 15 


\section{References}

Bandiera, O., Barankay, I., \& Rasul, I. (2012). Team incentives: Evidence from a firm level experiment. IZA discussion paper 6279, Institute for the Study of Labor (IZA). Retrieved August 18, 2012, from http://ftp.iza.org/dp6279.pdf.

Baron, D. P. (1979). Investment Policy, Optimality, and the Mean-Variance Model. The Journal of Finance, 34(1), 207-232.

Blount, S. (1995). When social outcomes aren't fair: The effect of causal attributions on preferences. Organizational Behavior and Human Decision Processes, 63(1), 131-144.

Borghans, L., Duckworth, A. L., Heckman, J. J., \& ter Weel, B. (2008). The economics and psychology of personality traits. Journal of Human Resources, 43(4), 972-1059.

Bramoullé, Y., \& Kranton, R. (2007a). Risk-sharing networks. Journal of Economic Behavior and Organization, 64, 275-294.

Bramoullé, Y., \& Kranton, R. (2007b). Risk sharing across communities. American Economic Association Papers and Proceedings, 97(2), 70-74.

Breton, M., St-Amour, P., \& Vencatachellum, D. (2003). Dynamic production teams with strategic behavior. Journal of Economic Dynamics \& Control, 27(5), 875-905.

Cadsby, B. C., Song, F., \& Tapon, F. (2007). Sorting and incentive effects of payfor-performance: An experimental investigation. The Academy of Management Journal, 50(2), 387-405.

Charness, G. (2004). Attribution and reciprocity in an experimental labor market. Journal of Labor Economics, 22, 665-688.

Chiang, S. H., \& Mahmud, A. S. (2008). Federations, coalitions, and risk diversification. Public Choice, 137, 403-426.

Cooper, L. C., Dyck, B., \& Frohlich, N. (1992). Improving the effectiveness of gainsharing: The role of fairness and participation. Administrative Science Quarterly, 37(3), 471-490.

Costa, P. T., \& McCrae, R. R. (1989). The NEO PI/FFI manual supplement. Odessa, FL: Psychological Assessment Resources.

Curme, M., \& Stefanec, N. (2007). Worker quality and labor market sorting. Economic Letters, 96, 202-208.

Dave, C., Eckel, C. C., Johnson, C. A., \& Rojas, C. (2010). Eliciting risk preferences: When is simple better? Journal of Risk and Uncertainty, 41(3), 219-243.

Dohmen, T., \& Falk, A. (2011). Performance pay and multidimensional sorting: Productivity, preferences, and gender. American Economic Review, 101(2), 556-590.

Eisenhardt, K. M., \& Schoonhoven, C.B. (1996). Resource-based view of strategic alliance formation: Strategic and social effects in entrepreneurial firms. Organizational Science, 7(2), 136--150. 
Eriksson, T., Poulsen, A., \& Villeval, M. C. (2009). Feedback and incentives: Experimental evidence. Labour Economics, 16(6), 679-688.

Eriksson, T., \& Villeval, M. C. (2008). Performance-pay, sorting and social motivation. Journal of Economic Behavior and Organization, 68(2), 412-421.

Franck, E., \& Nüesch, S. (2010). The effect of talent disparity on team production in soccer. Journal of Economic Psychology, 31(2), 218-229.

Fischbacher, U. (2007). Zurich toolbox for readymade economic experiments. Experimental Economics, 10(2), 171-178.

Gaynor, M., \& Gertler, P. (1995). Moral hazard and risk spreading in partnerships. RAND Journal of Economics, 26(4), 591-613.

Gerlitz, J. Y., \& Schupp, J. (2005). Zur Erhebung der Big-Five-basierten Persönlichkeits-merkmale im SOEP[Assessment of the Big Five InventorySOEP]. DIW Research Notes 4. Retrieved September 2, 2011, from http://www.diw.de/documents/publikationen/73/43490/rn4.pdf.

Greiner, B. (2004). The online recruitment system ORSEE 2.0 - A guide for the organization of experiments in economics. University of Cologne Working Paper Series in Economics 10, University of Cologne, Germany. Retrieved September 2, 2011, from http://www.luiss.it/hey/ambiguity/papers/Greiner_2004.pdf

Griesinger, D. W., \& Livingston, J.W. (1973). Towards a model of interpersonal motivation in experimental games. Behavioral Science, 18, 173-188.

Grossman, G. M. (2004). The distribution of talent and the pattern and consequences of international trade. The Journal of Political Economy, 112(1), 209-239.

Hamilton, H. B., Nickerson, J. A., \& Owan, H. (2003). Team incentives and worker heterogeneity: An empirical analysis of the impact of teams on productivity and participation. Journal of Political Economy, 111(3), 465-497.

Holmstrom, B. (1982). Moral hazard in teams. The Bell Journal of Economics, 13(2), 324-340.

Holt, C. A., \& Laury, S. K. (2002). Risk aversion and incentive effects. American Economic Review, 92(5), 1644-1655.

Ivanova-Stenzel, R, \& Kübler, D. (2011). Gender differences in team work and team competition. Journal of Economic Psychology, 32(5), 797-808.

Kocher, M., Strauß, S., \& Sutter, M. (2006). Individual or team decision-making Causes and consequences of self-selection. Games and Economic Behavior, $56(2), 259-270$.

Königstein, M., \& Ruchala, G. K. (2007). Performance pay, group selection and group performance. Bonn: Forschungsinstitut zur Zukunft der Arbeit. IZA discussion paper No. 2697. Retrieved September 2, 2011, from http://papers.ssrn.com/sol3/papers.cfm?abstract_id=981175.

Kvaløy, O., \& Olsen, T. E. (2006). Team incentives in relational employment contracts. Journal of Labor Economics, 24(1), 139-169. 
Lazear, E. P. (2000). Performance pay and productivity. American Economic Review, 90(5), 1346-1361.

Li, H., \& Suen, W. (2000). Risk sharing, sorting, and early contracting. Journal of Political Economy, 108(5), 1058-1091.

Liebrand, W. G. (1984). The effect of social motives, communication and group size on behavior in an N-person multi-stage mixed-motive game. European Journal of Social Psychology, 14, 239-264.

McAffee, R. P., \& McMillan, J. (1991). Optimal contracts for teams. International Economic Review, 32(3), 561-577.

Niederle, M., \& Vesterlund, L. (2007). Do women shy away from competition? Do men compete too much? Quarterly Journal of Economics, 122(3), 10671101.

Rothschild, M., \& Stiglitz, J. E. (1970). Increasing Risk: I. A Definition. Journal of Economic Theory, 2(3), 225-243.

Sloof, R., \& van Praag, C. M. (2010). The effect of noise in a performance measure on work motivation: A real effort laboratory experiment. Labour Economics, 17(5), 751-765.

Sonnemans, J., van Dijk, F., \& van Winden, F. (2006). On the dynamics of social ties structures in groups. Journal of Economic Psychology, 27(2), 187-204.

Van Dijk, F., Sonnemans, J., \& van Winden, F. (2001). Incentive systems in a real effort experiment. European Economic Review, 45, 187-214.

Wehrung, D. A., Lee, K.-H., Tse, D. K. \& Vertinsky, I. B. (1989). Adjusting risky situations: A theoretical framework and empirical test. Journal of Risk and Uncertainty, 2(2), 189-212. 